\title{
Another violation of NIH
}

\section{Washington}

Cross-contamination between viais containing viruses being transported from Britain to California may have caused a San Diego scientist inadvertently to carry out experiments prohibited under the National Institutes of Health's guidelines for recombinant DNA research. This, at least, is the "working hypothesis" which Dr Samuel I. Kennedy, of the University of California at San Diego, offered last week to explain what may prove to be the third violation of the guidelines.

Dr Kennedy, who moved to California from the University of Warwick in 1977, has been studying the activity of several arboviruses. In particular, he has been looking at the ways in which virus reproduction is inhibited by naturally produced "defective interfering particles" containing only a fragment of the virus genetic material. Earlier this year, Dr Kennedy and his research assistants cloned what they thought were subgenomic fragments of the Sindbis virus, a cause of fever and skin rash carried by mosquitoes in parts of Africa, India and Australia.

Following "confusing" results of attempts to characterize the nucleotide sequences in the resultant recombinant DNA produced in disabled Escherichia coli, the cloned material was sent to the Public Health Laboratories in Berkeley for analysis. There it was discovered that the cloned fragments appeared to have derived not from Sindbis virus but from Semliki Forest virus, another arbovirus being studied in Kennedy's laboratory.

This raised difficulties, for although the Sindbis virus has been classified by the Center for Disease Control (CDC) as a Class 2 agent - which under the NIH guidelines could be cloned under P2 physical containment conditions - the classification of the Semliki virus was ambiguous.

Until recently, the Semliki virus, known primarily as a cause of headaches and fever, was considered even safer to work with than Sindbis virus. Three years ago, however, a German research worker died after being infected by a wild-type strain of the virus. As a result of this incident, CDC is considering classifying the Semliki Forest virus as $\mathrm{C} 3$, although subject to certain qualifications.

At the end of last month, NIH announced changes in their guidelines to allow viruses in this class to be cloned under P3 containment conditions. However, at the time when Dr Kennedy's experiments were carried out, the cloning of $\mathrm{C} 3$ agents was prohibited.

As soon as the university suspected that the NIH guidelines might have been violated, both the Institutional Biosafety Committee and the NIH's Office of Recombinant DNA Activities (ORDA) were informed. ORDA is now carrying out an investigation, and will eventually make recommendations to $\mathrm{NIH}$ Director $\mathrm{Dr}$ Donald Fredrickson on what action should be taken.

The ORDA investigation seems likely to concentrate on three aspects. First, how could the confusion between the two types of virus have occurred and was this the result of cross-contamination during transit from research laboratories in Britain?

Second, ORDA must determine what classification it would have given to the Semliki Forest virus if a cloning application had been made at the beginning of the year. Approval as a Class 2 agent would have Class 3 would have disallowed it. This problem is complicated by the fact that $\mathrm{CDC}$ classification of arboviruses is under revision. A European scientist was told by $\mathrm{NIH}$ earlier this year that although the Semliki virus would probably be considered to fall within Class 3 , in certain geographic locations and conditions of use it might be considered $\mathrm{C} 2$, permitting cloning under $\mathrm{P} 2$ containment.

Finally, ORDA will be looking closely at the procedures followed by Dr Kennedy and the university once a violation of the guidelines was suspected. Dr Kennedy permitted the experiment; approval as

\section{guidelines}

stopped work on the cloned fragments, and informed the Institutional Biohazard Committee of the apparent mix-up, as soon as the results of the laboratory tests were received at the end of last month. Some of his graduates students, however, had previously approached the head of the biology department, Dr Donald Helinski, expressing concern about preliminary results and taking a different view of the actions that ought to be taken.

Both university and NIH officials stress that there was no public hazard involved. "We were not even cloning the entire genetic information in the virus" says Kennedy, pointing out that even if it was Semliki virus, the guidelines allow this to be safely cloned under the P3 containment conditions that were in fact used.

The biggest impact of the incident is likely to be on public perception of how the guidelines are working. Since the NIH guidelines were introduced in 1976, there have been two reported violations. In one a scientist from the Harvard Medical School carried out experiments without the necessary prior clearance from NIH. In the other, San Francisco scientists conducted experiments with a plasmid vector before it had been officially approved.

David Dickson

\section{Small beer for scientists}

Scientists working for the British Civil Service are unlikely to be satisfied by the outcome of the arbitration on salary scales for 1980 , which was completed last week. After the arbitration award was made known, Mr William McCall, General Secretary of the Institution of Professional Civil Servants (IPCS), said that the outcome was disgraceful and that "if this is what the system now in force for settling the pay of scientists in the Civil Service produces, then the system will have to be changed"'.

There have been several bones of contention between the IPCS and the Civil Service Department since the first offer of salaries for 1980. The department's proposals (see Nature, 24 July) were especially mean to the higher grades of the scientific Civil Service - those in the grade of Senior Principal Scientific Officer were, for example, offered no increase except the annual increments to which they were contractually entitled.

The IPCS has complained consistently that the device of pay research for relating the salaries of higher civil servants to those of comparable groups of workers in the private sector undermines the principle that scientists within the Civil Service should be paid the same as other civil servants of comparable rank and that, in any case, the data on salaries earned by scientists in the private sector are insufficient as an accurate foundation for

\section{pay research.} meet these protests. The salaries of Senior Principal Scientific Officers will after all be increased by 3.2 per cent in 1980 compared with 1979 , taking the maximum salary in this grade to $£ 16,250$ a year, compared with the claim by the union for $£ 18,248$.

The salaries of Principal Scientific Officers, which ranged from $£ 8,613$ to $£ 11,343$ at the beginning of the year, are to be increased to between $£ 9,690$ and $£ 12,540$, figures which are increased by between 1.5 per cent and 4.1 per cent as a result of the tribunal's intervention.

Scientific Officers, earlier in the year earning between $£ 6,332$ and $£ 8,705$, are now to receive salaries increased by between 20 per cent (at the bottom of the scale) and 10 per cent (at the top). The salaries of lower grades will be increased by proportions not very different from the rate of inflation.

Even so, this will not go far to meet the complaint that the salaries of scientists in the Civil Service are less than those of people of similar rank - Principal Scientific Officers will, for example, be paid $£ 1,260$ a year less than Administrative Officers. made this new award are not known, and may never be, although a report on the issue will be published next month.
The Civil Service Arbitration Tribunal appears to have gone only a little way to

The reason why the arbitration tribunal 